\title{
Management of a Failed Implant Site with Guided Bone Regeneration, Reimplantation, and Root Submergence Technique
}

\author{
${ }^{1}$ Nitika Poonia, ${ }^{2}$ Hilde Morales, ${ }^{3}$ Lanka Mahesh
}

\section{ABSTRACT}

A patient with failed implant in relation to 44 was being referred to the dental office. Site 44 was reimplanted with $A B$ Dent dental implants, and guided bone regeneration was done with Smartbone ${ }^{\circledR}$ bone graft and resorbable collagen membrane. Root submerged technique was followed in relation to 45 . One year postoperative follow-up shows stable bone levels in relation to 44,45 , and 46 .

Keywords: Bone regeneration, Crown, Dental Implant.

How to cite this article: Poonia N, Morales H, Mahesh L. Management of a Failed Implant Site with Guided Bone Regeneration, Reimplantation, and Root Submergence Technique. Int J Oral Implantol Clin Res 2016;7(2):45-47.

Source of support: Nil

Conflict of interest: None

\section{INTRODUCTION}

Dental implants have become a predictable treatment modality, providing satisfactory functional response and esthetics to many with missing teeth. The process of osseointegration provided a cure for replacement of missing teeth with high success and survival rates. A systematic review by Albrektsson et $\mathrm{al}^{1}$ has determined the 5- and 10-year implant survival rate to be 97.7 and $92.8 \%$ respectively. However, the occurrence of dental implant failure is not rare and affects 2.7 to $47.1 \%$ of implants respectively. ${ }^{2-4}$ In another longitudinal study of 10 years, including 101 subjects with 246 implants, the prevalence rate of peri-implintitis was shown to be $4.7,11.2$, and 15.1 respectively, among periodontally healthy, moderate, and severe periodontal compromised individuals. ${ }^{5}$

Management of a failed dental implant varies depending upon the type of implant failure. From nonsurgical treatment to bone grafting and in some cases reimplantation are some of the treatment modalities that are

\footnotetext{
${ }^{1}$ Periodontist, ${ }^{2,3}$ Private Practitioner

${ }^{1}$ Colonel S Dental First, New Delhi, India

${ }^{2}$ Clinica M y M, Valladolid, Spain

${ }^{3}$ The Specialist Clinic, Saket, New Delhi, India

Corresponding Author: Lanka Mahesh, Private Practitioner The Specialist Clinic, Saket, New Delhi, India, e-mail: drlanka. mahesh@gmail.com
}

considered in the process of treating a failed implant, ${ }^{6,7}$ a judgment which should be taken after a thorough clinical examination. With every failed implant, bone resorption takes place and bone grafting becomes mandatory. At the same time, patient compliance toward increasing time and cost of the procedure becomes difficult to manage, making the operator to opt for alternative documented treatment options, such as root submerged technique (RST). ${ }^{8}$

\section{CASE REPORT}

A 33-year-old female patient was referred to the dental office with $A B$ Dent dental implants placed in relation to 44 and 46 , out of which 44 had failed (Figs $1 A$ and B). The implant was removed and reimplantation was done with

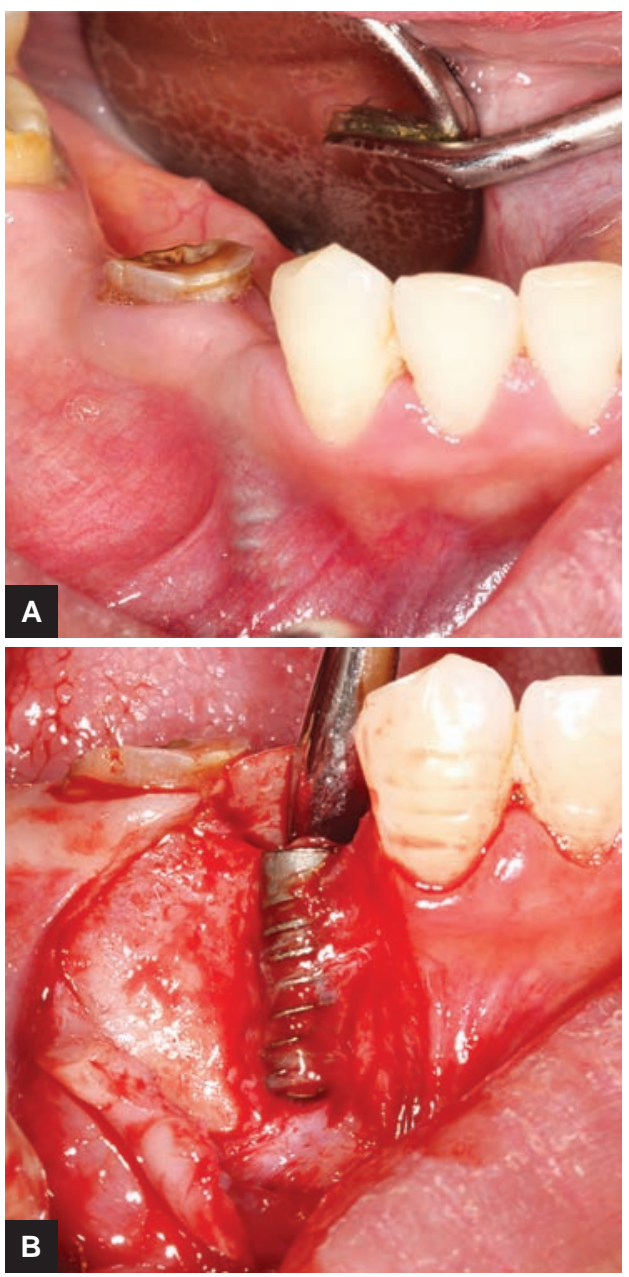

Figs $1 \mathrm{~A}$ and B: Failed implant w.r.t. \#44 


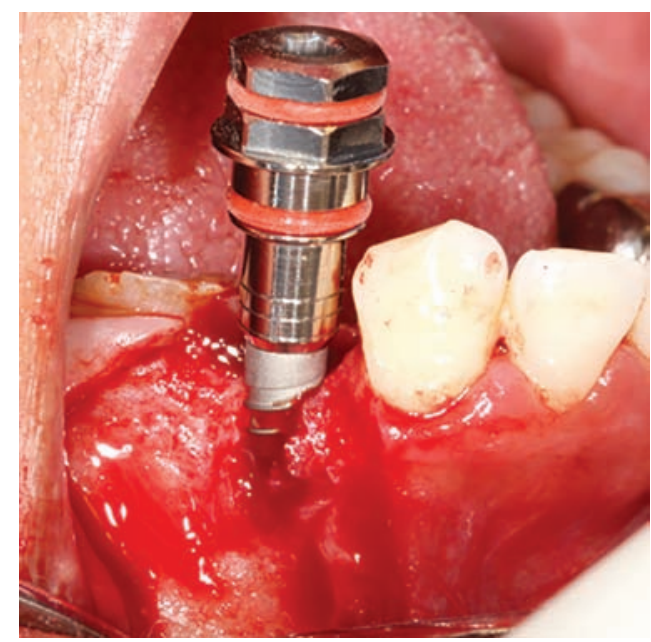

Fig. 2: Reimplanted \#44

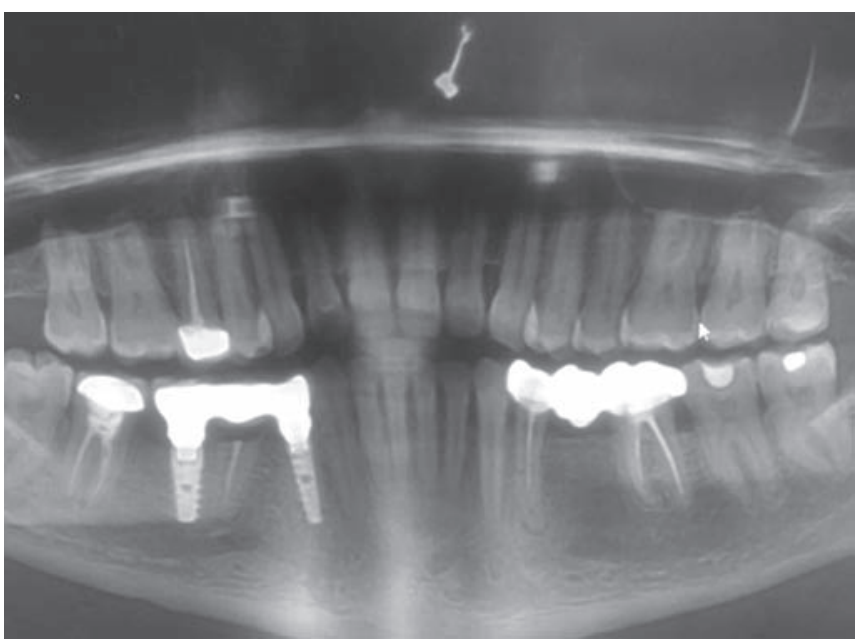

Fig. 4: One-year postoperative shows stable bone levels

correct lingualized osteotomy (Fig. 2). Guided bone regeneration was performed with Smartbone ${ }^{\circledR}$ bone graft and resorbable collagen membrane (RCM) (Figs $3 \mathrm{~A}$ and B).

At the second stage, root of 45 was left submerged. One year follow-up showed stable bone levels with the bone graft and RST (Fig. 4).

\section{DISCUSSION}

In the last few years, the replacement of missing teeth with a dental implant has increased, giving rise to biological complications and faulty placements of implants. However, implant failure is multifactorial and mainly depends upon patient-related factors, such as general patient health status, smoking habits, quantity and quality of bone, oral hygiene maintenance, etc. ${ }^{9-11}$ Implant characteristics, such as dimensions, coating, loading, and implant surface also play an important role. ${ }^{9-11} \mathrm{~A}$ Cochrane systematic review reported that significantly more peri-implantitis occurs at 3 years of loading around implants with roughened surfaces when compared with
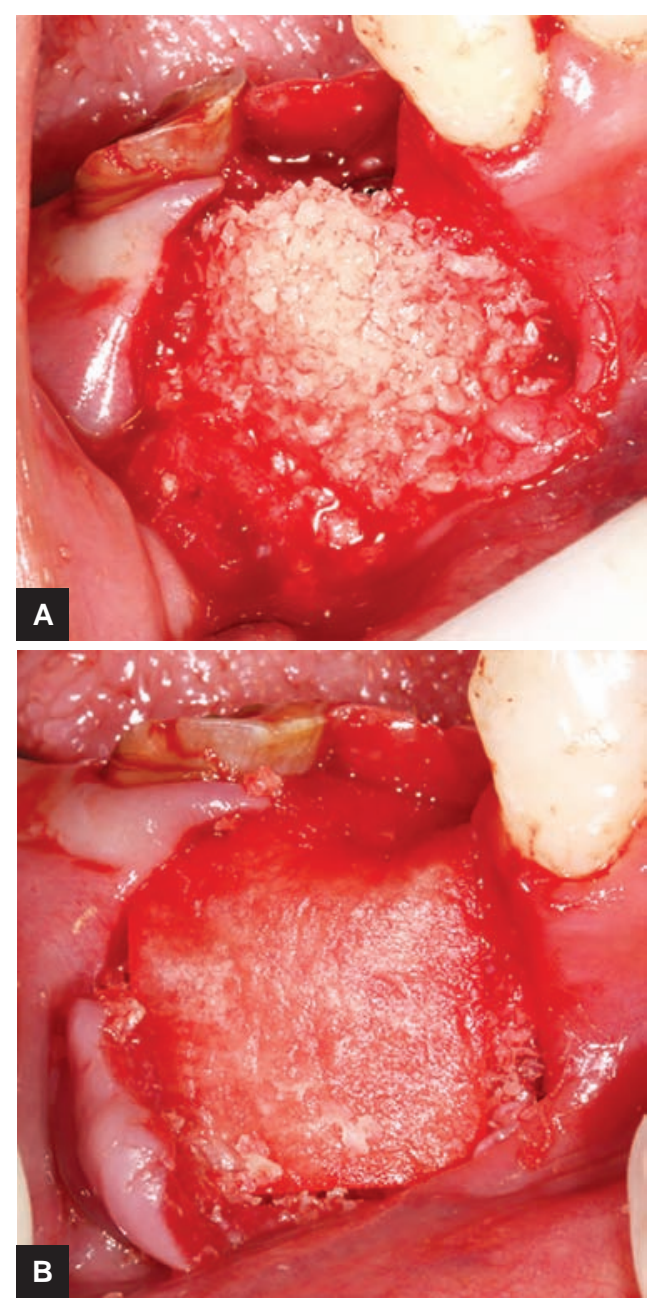

Figs 3A and B: Guided bone regeneration with Smartbone ${ }^{\circledR}$ bone graft and RCM

turned (machined) Brånemark implants. ${ }^{12}$ Yet another important reason of implant failure is based on its location, and clinician's experience ${ }^{9-11}$ jeopardizes the ability of functional and esthetic restoration. ${ }^{13}$

To obtain an esthetic and functional integrity, the underlying alveolar bone frame must be present to support the implant, ${ }^{8}$ but as the implant fails, it also resorbs the bone around it, making the patient to undergo further treatment of hard and soft tissue regrafting. In the present case, Smartbone was used as the bone graft material. It is an osteoconductive material comprising bovine bone, nutrient cells, and biodegradable polymers, enhancing and promoting the cascade of osteogenic process. Another advantage of this bone graft is that it is also available in the form of blocks and can be used to graft huge areas of lost alveolar bone as was seen in this case.

Tarnow et $\mathrm{al}^{14}$ have suggested that if the distance between adjacent implants is less than $3 \mathrm{~mm}$, the height of the alveolar bone decreases, giving rise to procedures, such as RST, which involves resecting the crown of a tooth, covering it with a buccal or buccolingual flap, and submerging the root. ${ }^{15}$ The procedure that was followed in this case 
was that the root of 45 was left submerged in the bone and no further attempt was made to extract it, preventing bone resorption after tooth extraction, ${ }^{8}$ and creating a natural pontic to maintain the ridge frame. Authors, such as Guyer, ${ }^{16}$ Plata et al, ${ }^{17}$ Bowers et al, ${ }^{18}$ Salama et al ${ }^{8}$ have reported successful treatments and maintenance of bone height with RST. One year follow-up of the present case confirms the aforementioned advantages.

\section{CONCLUSION}

Management of a failed implant sometimes becomes difficult; however, the literature provides various treatment options and huge treatment modalities to save a failing implant. But in the case of a failed implant, reimplantation remains the only option available. As seen in the reported case, reimplantation was done with corrected lingualized osteotomy and RST was followed to prevent further bone resorption and maintain patient compliance.

\section{REFERENCES}

1. Albrektsson T, Donos N, Working Group 1. Implant survival and complications. The third EAO consensus conference 2012. Clin Oral Implants Res 2012 Oct;23(Suppl 6):63-65.

2. Zitzmann NU, Berglundh T. Definition and prevalence of peri-implant diseases. J Clin Periodontol 2008 Sep;35(Suppl 8): 286-291.

3. Koldsland OC, Scheie AA, Aass AM. Prevalence of peri-implantitis related to severity of the disease with different degrees of bone loss. J Periodontol 2010 Feb;81(2):231-238.

4. Albrektsson T, Buser D, Sennerby L. Crestal bone loss and oral implants. Clin Implant Dent Relat Res 2012 Dec;14(6):783-791.

5. Roccuzzo M, De Angelis N, Bonino L, Aglietta M. Ten-year results of a three-arm prospective cohort study on implants in periodontally compromised patients. Part I: implant loss and radiographic bone loss. Clin Oral Imp Res 2010 May;21(5): 490-496.
6. Mishler OP, Shiau HJ. Management of peri-implant disease: a current appraisal. J Evid Base Dent Pract 2014 Jun;14 (Suppl):53-59.

7. Armas J, Culshaw S, Savarrio L. Treatment of peri-implant diseases: a review of the literature and protocol proposal. Dent Update 2013 Jul-Aug;40(6):472-480.

8. Salama M, Ishikawa T, Salama H, Funato A, Garber D. Advantages of the root submergence technique for pontic site development in esthetic implant therapy. Int J Periodontics Restorative Dent 2007 Dec;27(6):521-527.

9. Levin L, Schwartz-Arad D. The effect of cigarette smoking on dental implants and related surgery. Implant Dent 2005 Dec;14(4):357-361.

10. Nitzan D, Mamlider A, Levin L, Schwartz-Arad D. Impact of smoking on marginal bone loss. Int J Maxillofac Implants 2005 Jul-Aug;20(4):605-609.

11. Porter JA, von Fraunhofer JA. Success or failure of dental implants? A literature review with treatment considerations. Gen Dent 2005 Nov-Dec;53(6):423-432.

12. Esposito M, Murray-Curtis L, Grusovin MG, Coulthard P, Worthington HV. Interventions for replacing missing teeth: different types of dental implants. Cochrane Database Syst Rev 2007 Oct;4:CD003815.

13. Levin L. Dealing with dental implant failures. J Appl Oral Sci 2008 May-Jun;16(3):171-175.

14. Tarnow DP, Cho SC, Wallace SS. The effect of inter-implant distance on the height of inter-implant bone crest. J Periodontol 2000 Apr;71(4):546-549.

15. Howell F. Retention of alveolar bone by endodontic root treatment. Seminario Annual del Grupo de EstudiosDentales USC de Mexico 23, May 1970.

16. Guyer SE. Selectively retained vital roots for partial support of overdentures: a patient report. J Prosthet Dent 1975 Mar;33(3):258-263.

17. Plata RL, Kelln EE, Linda L. Intentional retention of vital submerged roots in dogs. Oral Surg Oral Med Oral Pathol 1976 Jul;42(1):100-108.

18. Bowers GM, Chadroff B, Carnevale R, Mellonig J, Corio R, Emerson J, Stevens M, Romberg E. Histologic evaluation of new attachment apparatus formation in humans. Part II. J Periodontol 1989 Dec;60(12):675-682. 